\title{
A microcomputer system for temperature biotelemetry
}

\author{
CHRISTOPHER L. CUNNINGHAM and JOANNA PERIS \\ Oregon Health Sciences University, Portland, Oregon
}

\begin{abstract}
A microcomputer (Apple II) system for recording body temperature measured by a commercially made, implantable biotelemetry device (Mini-Mitter) is described. The system includes an inexpensive radio receiver interface circuit and software written in BASIC and 6502 assembly language. The utility of the system is illustrated in a study that shows that various handling procedures (including that normally involved in rectal temperature measurement) elevate body temperature in rats.
\end{abstract}

Body temperature often serves as the primary dependent variable in studies of thermoregulation, circadian rhythms, and drug action. In recent years, it has become an increasingly popular measure in studies of drug tolerance and the role of behavioral processes (e.g., learning) in the development of tolerance (see review by Cunningham, Crabbe, \& Rigter, in press). However, the most common technique for recording core body temperature from rodents over extended periods of time is rather tedious and time-consuming, inasmuch as it requires repeated manual insertion of a rectal probe (see, e.g., Mansfield \& Cunningham, 1980; Siegel, 1978). Not only is this technique prone to error from several sources (e.g., variability in depth and duration of probe insertion, incorrect reading of thermometer), but there also is evidence that the handling involved in taking a rectal temperature actually alters body temperature (see, e.g., Briese \& de Quijada, 1970).

This paper describes a microcomputer-based system for using a commercially made, implantable biotelemetry device to record body temperature automatically in freely moving rats. The system uses an inexpensive transistor radio that has been modified in a simple way to provide a digital signal input to an Apple II microcomputer. A software package consisting of an Applesoft BASIC program and a clock-interrupt-driven machine language routine permits continuous real-time evaluation of body temperature, both for visual display and permanent storage on floppy disk. In order to illustrate the utility of the system and to show the advantage of using biotelemetry to record body temperature, we also report data on the thermic effects of various handling procedures, including rectal temperature measurement.

This research was supported in part by a research grant from the Medical Research Foundation of Oregon and NHLBI Training Grant HL07332. Requests for additional information should be addressed to the authors at: Department of Medical Psychology L470, Oregon Health Sciences University, Portland, Oregon 97201.

\section{BIOTELEMETRY DEVICE}

The biotelemetry device (Mini-Mitter Co., Inc., Sunriver, Oregon, Model M; approximate cost $=\$ 38$ ) consists of two thermistors and a battery-operated transmitter contained in a small, nontoxic, waterproof plastic capsule $(12 \times 19 \mathrm{~mm}, 2.3 \mathrm{~g})$. The device emits an AM band signal at a rate proportional to the surrounding temperature (approximately $24 \mathrm{~Hz}$ between $35-40{ }^{\circ} \mathrm{C}$ ). Each Mini-Mitter unit must be calibrated beforehand in a heated water bath, and the time interval between signal pulses (or the number of pulses per unit time) can be used to index temperature $\left(.1^{\circ} \mathrm{C}\right.$ resolution). The manufacturer specifies a transmission range of 2-3 ft and a battery life of 2-3 months.

\section{RECEIVER INTERFACE CIRCUIT}

The signal transmitted by the Mini-Mitter can be detected as a clicking sound from the speaker of an ordinary AM radio. In order to provide a digital input signal for the Apple II, the speaker from a 9-V transistor radio was replaced by a small board containing an IC circuit. This circuit (shown in Figure 1) detects the Mini-Mitter signal and outputs a short, positive squarewave pulse that can be delivered directly to a TTL ("pushbutton") input on the Apple II game-connector port.

The circuit consists of two main stages. In the first stage, a 20-ohm resistor (R1) has replaced the radio speaker, and the signal is capacitively coupled to the inverting input of a precision op-amp (LM308N) that is wired for single-polarity operation. The noninverting input is tied directly to the positive side of the power supply, which results in a normally high output level in the absence of an input signal. An input signal of sufficient magnitude will drive the output of the op-amp low. This will trigger the second stage of the circuit, a simple one-shot (NE555) that provides a timed output pulse for the computer. The duration of the one-shot 


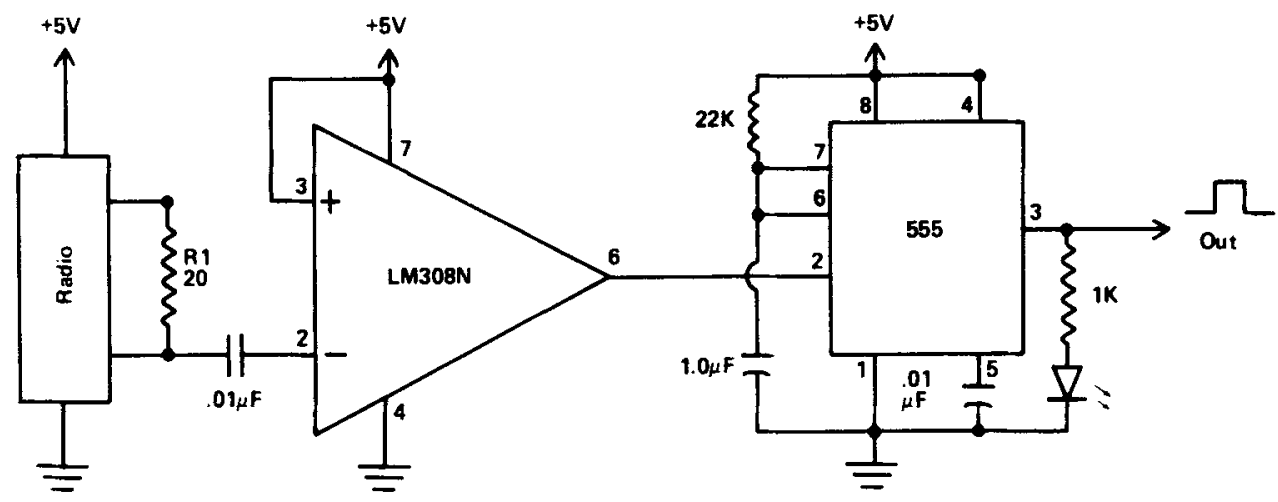

Figure 1. Circuit diagram for the radio receiver interface. The numbers next to the leads from each IC indicate the pin numbers on 8-pin DIPs. The output lead, $+5-\mathrm{V}$, and ground terminals all connect to pins on the Apple Il game-connector port.

pulse must be shorter than the shortest interval between signal pulses, but of sufficient duration to be detected by the computer program (see Software section). In the circuit shown in Figure 1, the duration of the output pulse is approximately $30-40 \mathrm{msec}$ and can be varied by changing the values of the resistor and capacitor connected to Pins 6 and 7. The output pulse also activates an LED mounted on the side of the radio. This provides visual feedback that is helpful for adjusting the radio controls.

In order to minimize noise, the radio should be tuned to a relatively "quiet" part of the AM band (the lowest frequency, $550 \mathrm{kHz}$, works well). Sensitivity (range) can be controlled simply by adjusting the volume knob on the radio. The entire circuit, including the radio, can be powered by the $+5 . \mathrm{V}$ supply available at the gameconnector port of the Apple II. The range of the receiver can be increased somewhat by increasing the supply voltage, up to 9-10 V. However, this requires an external power supply and additional circuitry to convert the one-shot pulse to TTL levels.

The radio used in this application (Dyna-Tone, Model 768) was obtained from a local variety store at a cost under $\$ 4.00$. The two IC chips are available in 8-pin DIPs and can be mounted end to end in a single 16-pin DIP socket on a small circuit board (e.g., Radio Shack No. 276-159) that fits inside the radio case. The total cost for the radio and parts was less than $\$ 9.00$.

\section{SOFTWARE}

The software for recording body temperature consists of an Applesoft BASIC program (SAMPLE.MITTER) and a clock-internupt routine written in 6502 assembly language (MINIMITTER.1). Complete commented listings appear in the Appendix. These programs were developed for an Apple II+ microcomputer with $48 \mathrm{~K}$ RAM memory and at least one disk drive (DOS 3.3). In addition to the receiver interface circuit, the only other required hardware is a clock card capable of providing a $100-\mathrm{Hz}$ interrupt pulse. The system uses a simple homemade clock card plugged into peripheral slot 4 , but it also works with a Mountain Hardware or similar commercially made clock card.

The software is designed to run an experimental session in which multiple timed samples (up to 255 samples, each 1-256 sec long) are taken at fixed intervals $(0-255 \mathrm{sec})$ and stored in memory. The raw datum is the average interval between signal pulses during each sample period (.01-sec resolution). Using the slope and intercept of the Mini-Mitter's calibration curve, these values are transformed to temperature (in ${ }^{\circ} \mathrm{C}$ ), and both the mean interval and the temperature are displayed on the monitor screen at the end of each sample period. The program also displays a countdown timer (showing the number of seconds remaining in the sample or intersample period), a signal counter, the duration of the most recent intersignal interval (in milliseconds), the sample number, and whether the sample is "on" or "off." The session terminates automatically after the appropriate number of samples has been collected, and the experimenter is given an opportunity to store the data on disk.

The heart of the program is the machine language clock-interrupt routine that is responsible for precise timing of the sample and intersample periods and for timing and evaluating the intervals between Mini-Mitter signals. This routine is loaded into memory (as a binary file) by the Applesoft BASIC program (Line 90). After the BASIC program receives the session parameters from the experimenter and initializes the program variables, the interrupt routine is initialized (Line 220). A screen message then prompts the experimenter to "press any key" to begin the session. The session actually begins $2.3 \mathrm{sec}$ later with the first sample period. At this point, the BASIC program enters a loop (Lines 250370 ) that provides a continuous updating of the screen information described earlier. 
While Applesoft executes the BASIC program loop, the clock-interrupt pulse "simultaneously" enables the machine language routine to be executed 100 times per second. Each time it is entered, this routine checks the status of the Mini-Mitter signal and updates the session timers. The interval between successive Mini-Mitter signals is timed simply by counting the number of clock pulses that occur between the onsets of one-shot pulses from the receiver interface. Because those pulses will not be synchronized with the clock card, their duration must be at least as long as the interval between clock pulses. Otherwise, input signals may be missed. Since the program looks for signal onsets, longer duration input pulses will cause no problem as long as there is at least one clock period $(10 \mathrm{msec})$ between the offset of one input pulse and the onset of the next.

While monitoring Mini-Mitter signals, the clockinterrupt routine does more than simply count the number of input pulses. It also provides a way of dealing with the two major kinds of signal error. One kind of error comes from sources of radio interference in the laboratory environment. For example, the operation of an electromechanical device (relay, solenoid) in the same room as the receiver is quite capable of triggering an output pulse. The other kind of error occurs when the Mini-Mitter is temporarily out of range (i.e., a missing signal). Changes in the orientation of the transmitter coil relative to the antenna coil can sometimes result in signal loss when the animal moves around the chamber. Reception is best when the loops of both coils are in the same plane. To combat these problems, the program evaluates the time interval between successive input pulses against two kinds of criteria-one based on the absolute value of the intersignal interval and the other based on the relative change in interval duration from one signal to the next. If the interval of time preceding a given input signal does not meet both criteria, it is not included in the computation of average intersignal interval for that sample period. Thus, when errors occur, the sample value is based on less than $100 \%$ of the specified sample period.

The criterion values are passed to the machine language routine during the initial portion of the BASIC program (Line 200) and, if necessary, can be changed easily by the experimenter. In our studies, the absolute lower and upper limits for intersignal intervals have been set at 200 and $500 \mathrm{msec}$, respectively. On average, across MiniMitters, this permits temperatures ranging between $33-43^{\circ} \mathrm{C}$. The relative change criterion has been set at $20 \mathrm{msec}$. In other words, a given interval is accepted only if it is vithi- $20 \mathrm{msec}$ (in either direction) of the most recent "good" interval (and within the absolute limits). If the error condition persists for a long period of time, it is possible for the program to begin to reject legitimate inputs on the basis of the relative-change criterion. To minimize this problem, the program automatically readjusts the criterion signal interval whenever an error condition lasts longer than 2 con- secutive seconds (i.e., the most recent interval is used as the value for the "last good interval"). This ordinarily corrects any problem in a matter of seconds if the signal is good. So far, this overall approach for handling signal errors has been quite useful.

At the end of each sample period, the machine language routine automatically passes the sample data (i.e., sample number, signal count, sum of "good" intersignal intervals) to BASIC integer variables (SN\%, $\mathrm{LC} \%$, and LS\%, respectively). The BASIC program then computes the mean intersignal interval, converts that to temperature, and stores the information in a twodimensional array, D( ) (Lines 310-360). The BASIC program also provides feedback on the extent of any error problems by displaying and storing the percentage of time during each sample period in which "acceptable" signals were recorded.

The session ends when the sample number equals the number of samples originally requested by the experimenter (Line 370). If desired, the contents of the data array can then be transferred to a sequential text file stored on floppy disk (Lines 390-440). The BASIC program shown in the Appendix can be expanded easily to provide summary statistics and a high-resolution graphics display of successive sample values.

\section{EFFECT OF HANDLING ON BODY TEMPERATURE}

In order to illustrate the utility of the present system and to show the advantages of biotelemetry, body temperature was recorded automatically from implanted Mini-Mitters in rats after they were picked up, pricked with a hypodermic needle, handled for rectal temperature measurement, or left undisturbed.

\section{Method}

The subjects were 12 adult male albino rats weighing an average of $638 \mathrm{~g}$. Each rat was anesthetized with halothane gas, and a Mini-Mitter was implanted surgically. The device was coated with Parafin/Elvax ${ }^{\circledR}$ to protect it from corrosion and had been previously calibrated in a heated water bath (range = $35-41^{\circ} \mathrm{C}$ ). A $1-2-\mathrm{cm}$ ventral midsagital incision was made about $5 \mathrm{~cm}$ below the diaphragm through both the skin and peritoneum, and a Mini-Mitter was inserted into the intraperitoneal cavity.

Temperature monitoring took place inside one of four identical clear plastic cages $(23 \times 20.5 \times 21 \mathrm{~cm})$ centered on an acrylic platform over the transistor radio. With this arrangement, an implanted Mini-Mitter always remained less than $21 \mathrm{~cm}$ from the radio antenna. Each cage was contained in a darkened, ventilated, sound-attenuating chamber (ambient temperature = $24^{\circ} \mathrm{C}$ ).

On each of 7 consecutive days, each rat was placed in the experimental chamber for $150 \mathrm{~min}$. On the first 3 days and on the final day, the animals were not disturbed. On the other days, each rat was subjected to one of three handling procedures $60 \mathrm{~min}$ after the session began. In one condition (Handled), the rat was picked up, placed in a plastic shoebox cage for $75 \mathrm{sec}$, and then returned to the test chamber. A second condition (Handled/Injection) involved a similar sequence, but after $60 \mathrm{sec}$ in the shoebox, the rat was picked up and a 25 -ga, 5/8-in. 
hypodermic needle was inserted into the abdomen for $15 \mathrm{sec}$ to mimic an ip injection (no fluid was actually injected). In the third condition (Handled/Rectal Probe), the rat was picked up and wrapped in a towel for $60 \mathrm{sec}$ while a lubricated, flexible thermistor probe (YSI Model 402) was inserted $6 \mathrm{~cm}$ into the rectum. The rats were assigned randomly to groups of four, and each group received these three treatments in a different order.

The Mini-Mitter output was sampled during consecutive $1-$ min periods (i.e., 0 -sec intersample interval), and temperature was averaged over 5-min blocks during each session. These data were collected with a version of our software written for the PDP-8/F, such that four subjects could be monitored simultaneously.

\section{Results}

On the handling treatment days, an average of $80.5 \%$ $($ SEM $=2.4)$ of each sample period was found to be acceptable according to the error-detection criteria. Body temperatures were elevated at the beginning of each session $\left(\right.$ mean $=38.6^{\circ} \mathrm{C}$ ), presumably due to the handling involved in transporting the rat to the experimental room and placing it in the test chamber. After the animal was placed in the chamber, temperatures declined gradually over time within each session, with the greatest changes occurring during the 1 st hour (about $0.8^{\circ} \mathrm{C}$ ).

Figure 2 shows mean body temperatures recorded for 5 -min periods just before and for $90 \mathrm{~min}$ after each of the handling treatments. The data shown for the Not Handled comparison were obtained by averaging temperatures recorded on the days just before and just after the handling-treatment days. As can be seen, body temperatures continued to decline under the Not Handled

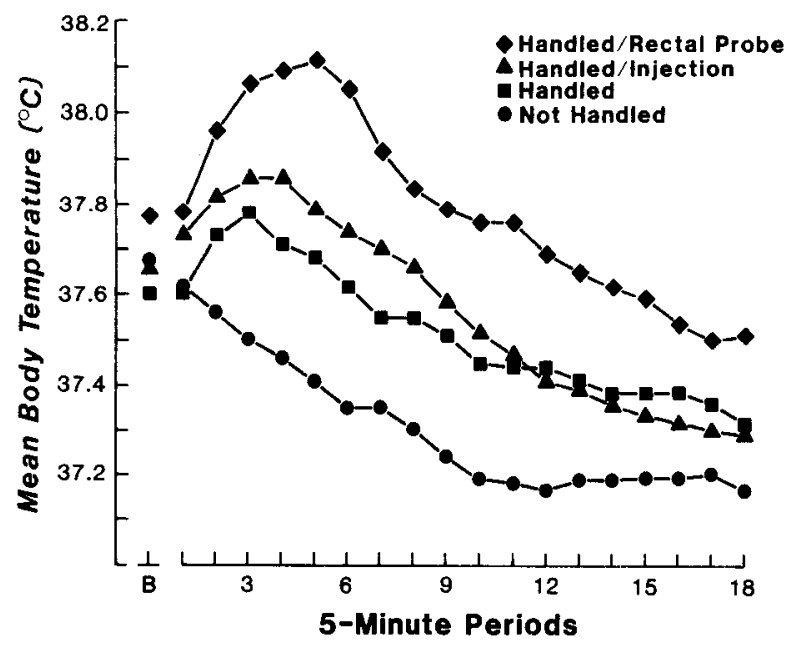

Figure 2. Mean body temperature (in ${ }^{\circ} \mathrm{C}$ ) recorded for 5 -min periods just before (B) and for $90 \mathrm{~min}$ after various handling treatments $(n=12)$. condition. However, each of the three handling treatments produced a hyperthermic reaction that persisted long after the animal was retumed to the test chamber. Furthermore, the magnitude and duration of the increase in temperature varied as a function of handling treatment. Rectal temperature measurement (Handled/ Rectal Probe) produced the largest and most persistent elevation.

The data shown in Figure 2 were subjected to a treatment $\mathrm{x}$ time periods analysis of variance that yielded a significant main effect of time periods $[F(18,198)=$ $25.4]$ and a significant interaction $[F(54,592)=2.3]$. Follow-up analyses that separately compared each handling treatment with the Not Handled condition also revealed statistically significant interactions, indicating that each handling procedure affected body temperature.

\section{CONCLUSION}

The microcomputer-controlled biotelemetry system described here offers a relatively inexpensive means of obtaining continuous measures of core body temperature. This approach not only eliminates the need to handle the animal, but it also reduces the experimenter's labor and increases the reliability of the temperature measurements. The data presented here establish the utility of this system and confirm previous findings that handling (including that commonly used to obtain rectal temperature measurements) can have a dramatic impact on core temperature (Blasig, Hollt, Bauerle, \& Herz, 1978; Briese, 1965; Briese \& de Quijada, 1970; Miles, 1962).

\section{REFERENCES}

Blasig, J., Hollt, V., Bauerle, U., \& Herz, A. (1978). Involvement of endorphins in emotional hyperthermia of rats. Life Sciences, 23, 2525-2532.

Briese, E. (1965). Hyperthermia in self-stimulating rats. Acta Physiologica Latinoamerica, 15, 357-361.

Briese, E., \& de QuiJada, M. G. (1970). Colonic temperature of rats during handling. Acta Physiologica Latinoamerica, 20, 97-102.

Cunningham, C. L., Crabae, J. C., \& Rigter, H. (in press). Pavlovian conditioning of drug induced changes in body temperature. Pharmacology and Therapeutics.

Mansfield, J. G., \& Cunningham, C. L. (1980). Conditioning and extinction of tolerance to the hypothermic effect of ethanol in rats. Journal of Comparative and Physiological Psychology, 94, 962-969.

MiLEs, G. H. (1962). Telemetering techniques for periodicity studies. Annals of the New York Academy of Science, 98, 858-865.

Sizael, S. (1978). Tolerance to the hyperthermic effect of morphine is a learned response. Journal of Comparative and Physiological Psychology, 92, 1137-1149. 
APPENDIX

Program Listings

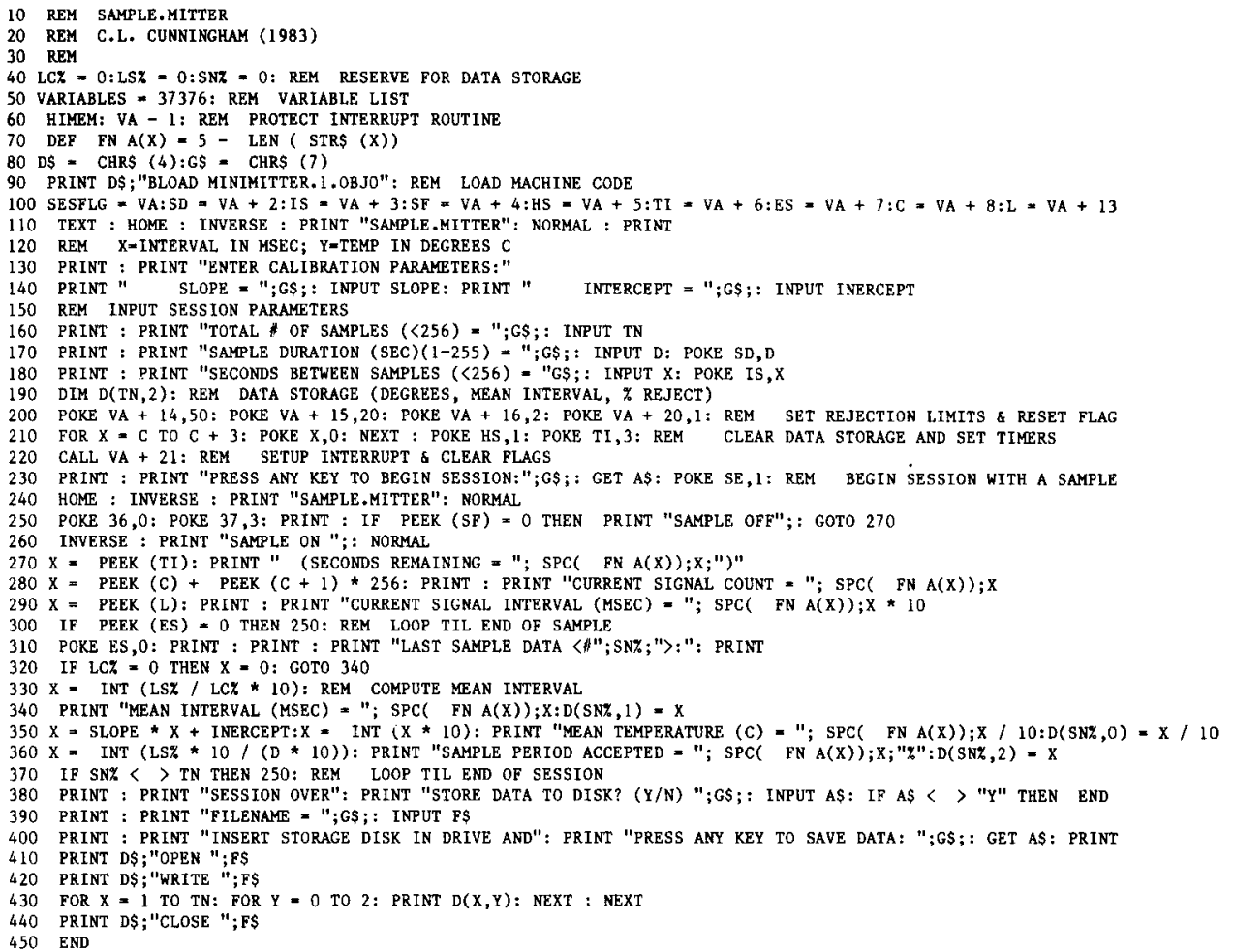

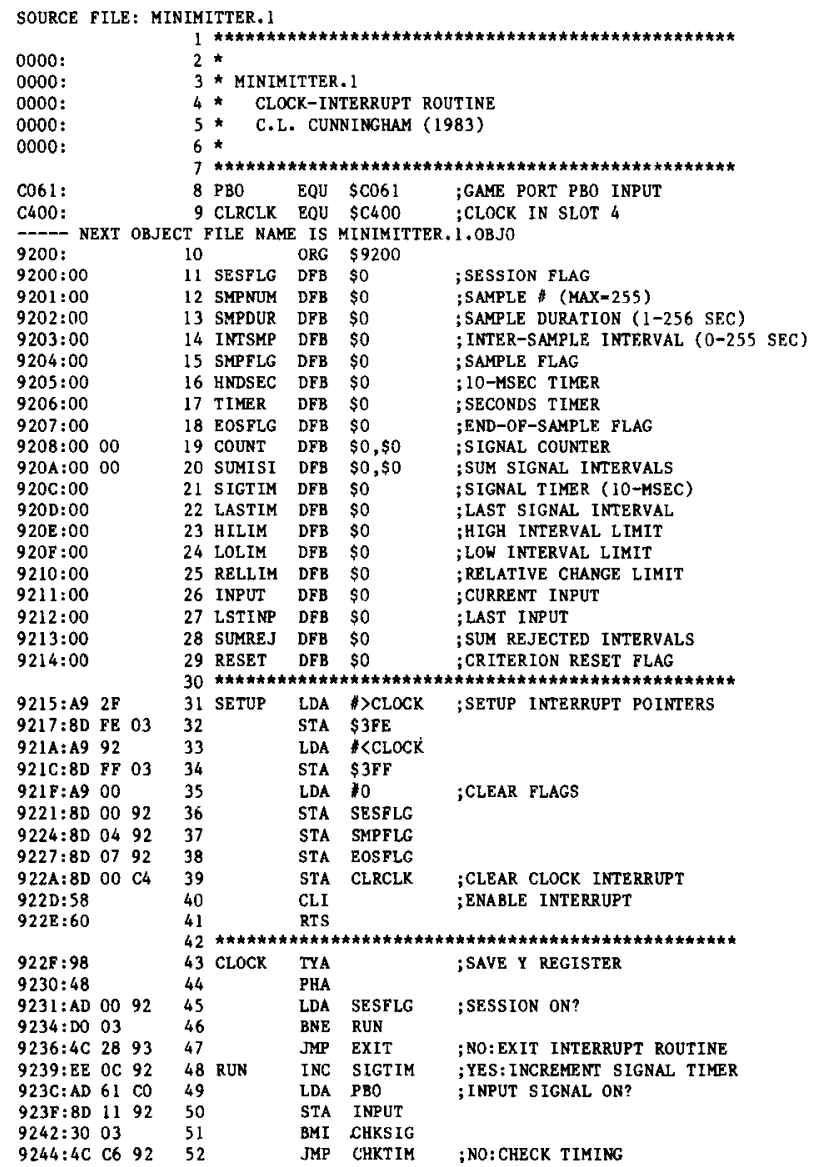




\begin{tabular}{|c|c|c|c|}
\hline $9247: A D$ & 12 & 92 & 53 \\
\hline $924 \mathrm{~A}: 10$ & 03 & & 54 \\
\hline $924 \mathrm{C}: 4 \mathrm{C}$ & C6 & 92 & 55 \\
\hline $924 \mathrm{~F}: \mathrm{AD}$ & oc & 92 & 56 \\
\hline $9252: C D$ & OF & 92 & 57 \\
\hline $9255: 90$ & $4 \mathrm{E}$ & & 58 \\
\hline 9257:CD & $\mathrm{OE}$ & 92 & 59 \\
\hline $925 \mathrm{~A}: \mathrm{B} 0$ & 49 & & 60 \\
\hline $925 \mathrm{C}: \mathrm{CD}$ & $O D$ & 92 & 61 \\
\hline $925 \mathrm{~F}: \mathrm{PO}$ & $1 \mathrm{C}$ & & 62 \\
\hline $9261: B 0$ & OB & & 63 \\
\hline $9263: 60$ & 10 & 92 & 64 \\
\hline $9266: \mathrm{CD}$ & OD & 92 & 65 \\
\hline $9269: B 0$ & 12 & & 66 \\
\hline $926 \mathrm{~B}: 4 \mathrm{C}$ & A5 & 92 & 67 \\
\hline $926 \mathrm{E}: 18$ & & & 68 \\
\hline $926 \mathrm{~F}: \mathrm{AD}$ & OD & 92 & 69 \\
\hline $9272: 6 \mathrm{D}$ & 10 & 92 & 70 \\
\hline $9275: \mathrm{CD}$ & OC & 92 & 71 \\
\hline $9278: B 0$ & 03 & & 72 \\
\hline $927 \mathrm{~A}: 4 \mathrm{C}$ & A5 & 92 & 73 \\
\hline $927 \mathrm{D}: \mathrm{EE}$ & 08 & 92 & 74 \\
\hline $9280: D 0$ & 03 & & 75 \\
\hline $9282: \mathrm{EE}$ & 09 & 92 & 76 \\
\hline $9285: 18$ & & & 77 \\
\hline $9286: A D$ & $0 \mathrm{C}$ & 92 & 78 \\
\hline $9289: 8 \mathrm{D}$ & $O D$ & 92 & 79 \\
\hline $928 \mathrm{C}: 6 \mathrm{D}$ & $O A$ & 92 & 80 \\
\hline $928 \mathrm{~F}: 8 \mathrm{D}$ & $\mathrm{OA}$ & 92 & 81 \\
\hline 9292:A9 & 00 & & 82 \\
\hline $9294: 6 \mathrm{D}$ & $\mathrm{OB}$ & 92 & 83 \\
\hline $9297: 8 \mathrm{D}$ & OB & 92 & 84 \\
\hline $929 \mathrm{~A}: \mathrm{A9}$ & 00 & & 85 \\
\hline $929 \mathrm{C}: 8 \mathrm{D}$ & 13 & 92 & 86 \\
\hline $929 \mathrm{~F}: 8 \mathrm{D}$ & 14 & 92 & 87 \\
\hline $92 \mathrm{~A} 2: 4 \mathrm{C}$ & $\mathrm{Cl}$ & 92 & 88 \\
\hline $92 \mathrm{AS}: \mathrm{AD}$ & 14 & 92 & 89 \\
\hline $92 \mathrm{AB}: \mathrm{DO}$ & 11 & & 90 \\
\hline $92 \mathrm{AA}: 18$ & & & 91 \\
\hline $92 \mathrm{AB}: \mathrm{AD}$ & OC & 92 & 92 \\
\hline $92 \mathrm{AE}: 6 \mathrm{D}$ & 13 & 92 & 93 \\
\hline $92 \mathrm{~B} 1: 8 \mathrm{D}$ & 13 & 92 & 94 \\
\hline $92 \mathrm{~B} 4: \mathrm{C9}$ & C8 & & 95 \\
\hline $92 \mathrm{~B} 6: 90$ & 09 & & 96 \\
\hline 92B8:EE & 14 & 92 & 97 \\
\hline $92 \mathrm{BB}: \mathrm{AD}$ & OC & 92 & 98 \\
\hline $92 \mathrm{BE}: 8 \mathrm{D}$ & OD & 92 & 99 \\
\hline $92 \mathrm{Cl}: \mathrm{A9}$ & 00 & & 100 \\
\hline $92 \mathrm{C3}: 8 \mathrm{D}$ & $\mathrm{OC}$ & 92 & 101 \\
\hline $92 \mathrm{C6}: \mathrm{CE}$ & 05 & 92 & 102 \\
\hline $92 \mathrm{Cg}: \mathrm{DO}$ & 5D & & 103 \\
\hline $92 \mathrm{CB}: \mathrm{A9}$ & 64 & & 104 \\
\hline $92 \mathrm{CD}: 8 \mathrm{D}$ & 05 & 92 & 105 \\
\hline $92 \mathrm{DO}: \mathrm{CE}$ & 06 & 92 & 106 \\
\hline 92D3:D0 & 53 & & 107 \\
\hline $92 D 5: A D$ & 04 & 92 & 108 \\
\hline $9208: D 0$ & ID & & 109 \\
\hline 92DA: $\mathrm{EE}$ & 04 & 92 & 110 \\
\hline 92DD: $\mathrm{EE}$ & 01 & 92 & 111 \\
\hline 92E0:AD & 02 & 92 & 112 \\
\hline $92 \mathrm{E} 3: 8 \mathrm{D}$ & 06 & 92 & 113 \\
\hline $92 \mathrm{E} 6: \mathrm{A} 9$ & 00 & & 114 \\
\hline $92 \mathrm{E} 8: 8 \mathrm{D}$ & 08 & 92 & 115 \\
\hline 92EB:8D & 09 & 92 & 116 \\
\hline $92 \mathrm{EE}: 8 \mathrm{D}$ & $O A$ & 92 & 117 \\
\hline $92 \mathrm{~F} 1: 8 \mathrm{D}$ & $O B$ & 92 & 118 \\
\hline $92 \mathrm{~F} 4: 4 \mathrm{C}$ & 28 & 93 & 119 \\
\hline $92 \mathrm{~F} 7: A 9$ & 00 & & 120 \\
\hline $92 \mathrm{F9}: 8 \mathrm{D}$ & 04 & 92 & 121 \\
\hline 92FC: EE & 07 & 92 & 122 \\
\hline $92 \mathrm{FF}: \mathrm{A} 0$ & 02 & & 123 \\
\hline $9301: A D$ & 09 & 92 & 124 \\
\hline $9304: 91$ & 69 & & 125 \\
\hline $9306: C 8$ & & & 126 \\
\hline $9307: A D$ & 08 & 92 & 127 \\
\hline $930 \mathrm{~A}: 91$ & 69 & & 128 \\
\hline $930 \mathrm{C}: \mathrm{AO}$ & 09 & & 129 \\
\hline $930 \mathrm{E}: \mathrm{AD}$ & $O B$ & 92 & 130 \\
\hline $9311: 91$ & 69 & & 131 \\
\hline $9313: C 8$ & & & 132 \\
\hline 9314:AD & $0 \mathrm{~A}$ & 92 & 133 \\
\hline $9317: 91$ & 69 & & 134 \\
\hline $9319: A 0$ & 11 & & 135 \\
\hline 931B:AD & 01 & 92 & 136 \\
\hline $931 \mathrm{E}: 91$ & 69 & & 137 \\
\hline $9320: A D$ & 03 & 92 & 138 \\
\hline $9323: F 0$ & B5 & & 139 \\
\hline $9325: 8 D$ & 06 & 92 & 140 \\
\hline $9328: A D$ & 11 & 92 & $1+1$ \\
\hline $932 \mathrm{~B}: 8 \mathrm{D}$ & 12 & 92 & 142 \\
\hline $932 \mathrm{E}: 68$ & & & 143 \\
\hline $932 \mathrm{~F}: \mathrm{A} 8$ & & & 144 \\
\hline $9330: A D$ & 00 & $C_{4}$ & 145 \\
\hline $9333:$ A5 & 45 & & 146 \\
\hline $9335: 40$ & & & 147 \\
\hline
\end{tabular}

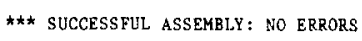

(Manuscript received October 31, 1983;

revision accepted for publication December 15, 1983.) 